\title{
CARTOGRAFIA TITIRITERA PARA A DESCOLONIZAÇÃO: Cuba, a ilha dos fantasmas ou Revolução dos Juancitos.
}

\section{CARTOGRAFÍA TITIRITERA PARA LA DESCOLONIZACIÓN: Cuba, La Isla de los fantasmas o la Revolución de los Juancitos.}

\section{PUPPETRY'S CARTOGRAPHY FOR THE DECOLONIZATION: Cuba, The Island of the Ghosts or the Revolution of the Juancitos.}

\section{Liliana Pérez Recio ${ }^{1}$}

\begin{abstract}
RESUMEN
Este artículo aborda La obra de Javier Villafañe en la producción del teatro de títeres cubano contemporáneo como elemento nutricio para la conformación de expresiones transculturales "descolonizantes" frente a los patrones coloniales de legitimación en un contexto poscolonial-socialista.
\end{abstract}

PALABRAS CLAVE: identidad cultural, Javier Villafañe, pos-colonialismo, teatro de animación, títeres, transculturación

\begin{abstract}
This article deals with the work of Javier Villafañe in the production of contemporary Cuban puppet theater as a nurturing element for the formation of "decolonizing" transcultural expressions in front of colonial patterns of legitimation in a postcolonial-socialist context.

KEYWORDS: cultural identity, Javier Villafañe, pos-colonialism, puppetry, theater of animation, transculturation
\end{abstract}

\footnotetext{
${ }^{1}$ Directora Fundadora, El Arca Teatro Museo de Títeres. Oficina del Historiador de la Ciudad de la Habana. Maestría en curso PPGT CEART UDESC. Orientadora Dra. Professora Fátima Costa de Lima, bolsa CAPES.
} 
En el centro de la isla de Cuba, más allá de las villas y antes del oriente, aún se habla de los ensabanados ${ }^{2}$ del Camagüey. Mascarada casi volátil creada como respuesta a la prohibición decimonónica del uso de máscaras en las fiestas de San Juan. Otras prácticas carnavalescas de estas celebraciones también remiten al legado europeo, igual que en las fiestas juninas en Brasil. Se dice que los festejos coincidían con la llegada de los monteros y las ventas del ganado. Poco queda de aquellas tradiciones tras el control estatal de los carnavales. Mi abuelo decía que en las familias nunca se hablaba de aparecidos o babujales porque esos mitos solo servían para encubrir la entrada furtiva de hombres en las casas de doncellas y viudas. El temor al babujal venía antecedido por un sonido aterrador que lo anunciaba, de forma tal que las personas se recogían en sus casas y no salían a la calle de noche. Fechorías bien encubiertas ocurrirían bajo el miedo al babujal. Todavía hay comunidades que alimentan temores como al "pájaro de la bruja" y se resisten a exponerse a su chillido nocturno. Para hablar de resonancias del teatro de títeres argentino en Cuba, hay que hablar de Javier Villafañe y para eso hay que hablar de Juancito y María o La calle de los fantasmas. Busquemos el "ojo de agua".

En 1934 Federico García Lorca estrena en Buenos Aires, en un gesto de retomada poética de la tradición titiritera española, El retablillo de Don Cristóbal. Asisten a la función jóvenes que van a diseminar el teatro de títeres en la América Latina de manera profesional, entre ellos Mané Bernardo, Ernesto Arencibia y Javier Villafañe. El 22 de octubre de 1935 el periódico La Nación, anuncia la primera función de Juan Pedro Ramos y Javier Villafañe en La Andariega, dice que presentarán una versión de Fausto, El fantasma; cuenta la leyenda que poco tiempo después se vieron con un público compuesto por muchos niños, tuvieron que improvisar, y así, en la propia génesis de este teatro de títeres anida su vocación por los más jóvenes, dando lugar a Juancito y

\footnotetext{
2 Ensabanado: En el Camagüey persona que cubre rápidamente su cuerpo con una sábana o mantel tomando la apariencia de fantasma que encubriendo su identidad hace burlas a las vecinas y transeúntes.
} 
Margarita, luego Juancito y María, y ya para 1936 se estrenaba como Aventuras del vigilante Juancito con el subtítulo, la Calle de los Fantasmas ${ }^{3}$.

En 1949, El retablillo... de Lorca es estrenado a su vez en la Habana por el Grupo Escénico Libre con Vicente Revuelta, pionero en cuanta proceso de investigación vivió el teatro cubano del siglo XX; asisten a la función los hermanos Carucha y Pepe Camejo4. En 1956 Pepe Carril junto a los hermanos Camejo constituyen el Guiñol Nacional de Cuba, colocando en su repertorio obras de Javier Villafañe, así lo harán también Dora Carvajal en La Carreta fundada en 1952 y el Teatro de Muñecos de la Habana en 1960. Entre 1961 y 1962 Los hermanos Camejo ofrecen cursos en las provincias que dejan creados los núcleos constitutivos de un teatro guiñol por cada provincia. En 1963 inauguran el Teatro Nacional de Guiñol, para entonces ya habían estrenado varios textos de Pelusín del Monte, creados por Dora Alonso. En 1965 el uruguayo Nicolás Loureiro diseña y construye para el Teatro de Muñecos de la Habana Juancito y María, que como tales se conservan hasta hoy en la colección de El Arca, Teatro Museo de Títeres. En 1975, se producde el parte aguas de la "parametración"5 y aún así se lee en el repertorio activo del Guiñol Nacional los textos de Javier Villafañe. Fue el año en que visitó Cuba como jurado del premio Casa de las Américas, quedó maravillado porque los niños lo confundían con Hemingway, como Lorca, fue a Santiago. Se le esperaba en 1996 como invitado al taller Internacional de Títeres de Matanzas, no tuvo tiempo de llegar. Ese fue el año en que hice votos de titiritera. Hoy me pregunto qué habría sentido Maese Trotamundos su hubiese sabido de cuántas mujeres han representado sus textos en la isla: Carucha Camejo, Dora Carvajal, dieron lugar a Miriam Sánchez, a Maribel López, Migdalia Seguí, Tamara Venereo, Lizet Días, Damaris Pacheco, Geraidys Brito, Emelia Díaz y tantas otras hasta la joven Yanelis Vignier: haciendo su "solo bufo a la cachiporra" de La Calle... guarecida en su pequeño retablo donde solo hay lugar para una titiritera.

\footnotetext{
${ }^{3}$ Ver en MEDINA, Pablo. Javier Villafañe, Antología. Buenos Aires, Editorial Sudamericana, 1999.

4 Ver en PÉREZ, Liliana. "Diálogo con Carucha Camejo". In: Revista Tablas. La Habana, Ediciones Alarcos, No. 2 de 2003.

${ }^{5}$ Crisis laboral en el sector de la cultura, donde las autoridades ministeriales separaban de sus puestos de trabajo a aquellos artistas que a su modo de ver no reunían lo parámetro ideológicos y morales para trabajar "para el pueblo".
} 
A propósito de retablos, qué habría dicho de saber que sus Juancitos en Cuba se hicieron mestizos, de edades, de colores, de materiales, de técnicas. Andariegos, los Juancitos y las marías dejaron hijos audaces que por el deseo de investigar, de ir más lejos, de empujar el horizonte, experimentaron mutaciones para habitar en teatro con luz negra, teatro con esperpentos, como títeres de varilla, de mesa, marotes.

Otros argentinos han dejado su legado para el desarrollo del teatro de figuras animadas en Cuba, es el caso de Juan Enrique Acuña cuyo libro fue publicado para el programa de estudio de las escuelas de arte del país. Roberto Espina, cuyas obras han sido estrenadas en varios grupos, así como Kike Sánchez y Fernando Tiell. Son de importante referencia teórica las publicaciones de autores como Mauricio Kartun, Pablo Medina, Ana Alvarado, Eduardo Di Mauro, Rafael Cursi. Ya en el siglo XXI, han impartido cursos Claudio Hochman, Fernán Cardama y Tito Loréfice. De igual forma la existencia del Museo Argentino del Títere creado por Mane Bernardo y Sarah Bianchi, ha sido inspirador para direccionar mi trabajo en función del patrimonio titiritero con vocación por la docencia y la investigación. A su vez, el desarrollo en términos académicos que ha logrado Argentina para la formación de titiriteros en los últimos 15 años, en comparación con Cuba sigue colocándolos en un lugar de referencia, al que miramos con admiración y sed de conocimientos, conscientes de los efectos acumulados por la carencia de espacios formativos en la isla.

En junio de 2016 fui invitada por el Dr. Mario Piragibe para participar en el Festival de Teatro de Animação do Triângulo Mineiro 2da CENA ANIMADA en la Universidad Federal de Uberlândia, 2016; que fuera dedicado al legado de los titiriteros argentinos en Brasil y de manera extensiva en América Latina. Cuando recibí la llamada respondí: “... pues claro que sí, en Cuba se han puesto 200 versiones de La Calle los fantasmas de Javier Villafañe, hay mucho material para trabajar, mucho que contar..." la convocatoria estaba muy ligada a este instante de mi trayectoria como investigadora dedicada a los asuntos patrimoniales por casi ocho años. 
Esta fue una respuesta empírica, dada desde el cuerpo después de 20 años de trabajo a lo largo del país llevando espectáculos titiriteros a los lugares más remotos de la geografía insular. La misma que diera la especialista del Consejo Nacional de las Artes Escénicas del Ministerio de Cultural Raíza Beltrán, encargada de recibir semana tras semana, por más de 10 años, el reporte de funciones de todas las provincias del país. Le pregunté, así, informalmente: Desde la función que realizas en tu departamento, recibiendo las cifras de público y funciones ¿cuál es la obra que más se pone en Cuba? Me dice de inmediato: “... la de los fantasmas, todos la ponen, pero el asunto está en el cómo!”

Y yo me quedo pensando en los mitos griegos y en las infinitas versiones de Electra y Edipo y Medea como matrices portadoras de un patrimonio que se trasmite y recompone en tanto palpita con su tiempo y su gente, cual cíclica resurrección dionisíaca, de forma tal que aún hacemos "teatro". Así, la pregunta ya presupone la propensión a la reiteración de títulos en la práctica teatral cubana.

De manera que al acometer el encargo de preparar la conferencia para Uberlândia se confirmó ante mí, con elocuencia, en las estadísticas captadas 6 sobre los títulos recurrentes en el repertorio activo de los 36 grupos titiriteros del país en 2014, con un margen de tolerancia de (+/- ) 2 años: La calle de los Fantasmas, de Javier Villafañe con una prevalencia del $42,7 \%$ frente a $L a$ Cucarachita Martina, texto cubano y parte del acervo latinoamericano compartido, con 22,2 \%, seguido de Caperucita Roja, primer cuento clásico adaptado para su representación con títeres con carácter profesional y por auspicio de la Academia de Arte Dramático en 1943, con 19,4 \%; para finalmente encontrar con un 13,8 \% de representaciones activas a Pelusín del Monte de Dora Alonso, cuya primera entrega fue escrita en 1956 por encargo del Guiñol Nacional de Cuba.

Para una compresión profunda de lo que narran los números, es necesario un análisis histórico social del contexto en que se producen. Veamos como desde

\footnotetext{
${ }^{6}$ En Cuba UNIMA. Catálogo publicado con motivo del Consejo de la UNIMA mundial realizado en Cuba en 2014. Se refiere a los grupos miembros de la UNIMA Cuba.
} 
la segunda mitad del siglo XIX ya José Martí está apuntando la situación de la región cuando cuestiona: “Cómo han de salir de las Universidades los gobernantes, si no hay Universidad en América donde se enseñe lo rudimentario del arte del gobierno, que es el análisis de los elementos peculiares de los pueblos de América?” (MARTÍ, 2005 [1891], 33). Una constante angustia, se expresa en los países poscoloniales, unas veces en las ansias de "ascender" para legitimarse en los parámetros de la cultura dominante que recibe o lo antecede y otras, por el contrario, en la búsqueda de autoafirmación desde la construcción de discursos nacionalistas.

(...) Aunque parecen invocar un origen en un pasado histórico con el cual continúan en correspondencia, en realidad las identidades tienen que ver con las cuestiones referidas al uso de los recursos de la historia, la lengua y la cultura en el proceso de devenir y no de ser; no "quiénes somos" o "de dónde venimos" sino en qué podríamos convertirnos, cómo nos han representado y cómo atañe ello al modo como podríamos representarnos. (HALL, 1996:01)

Con esta perspectiva, constatar la prevalencia de la obra de Javier Villafañe en Cuba, y por extensión en toda la región al sur del Río Bravo, como definiera José Martí el marco latinoamericano, podría conducirnos a percibirla como una matriz donde se articulan características, que de manera orgánica, manifiestan y propician una expresión contemporánea latinoamericana desde su condición transcultural.

Llamaron "criollo" al nacido en colonia, o tierras de ultramar. Nación, nacionalidad, aparecen directamente ligados al sitio donde se nace, aun cuando podemos hablar de pueblos en diáspora en los que pervive una conciencia de nación cultural independientemente del sitio de nacimiento. Así que nacer de este lado de la mar océano, trajo prontamente la conciencia de la alteridad y propició la diferenciación entre peninsulares y los nacidos en las colonias, siendo que todos eran españoles pero unos eran más españoles que otros. Cinco siglos después, esa herencia continúa expresándose en nuestras producciones simbólicas, en nuestra toma de decisiones. Seguimos siendo un destino exótico y bajo el techo académico con más o menos conciencia sobre ello los discursos van a buscar legitimación en la producción europea, no con una dinámica intercultural 
sino desde la condición de subalterno, en tanto las voces locales permanecen preteridas.

Pese a todas las intermitencias entre crisis y bonanzas socioeconómicas, el teatro de títeres en Cuba, desde la segunda mitad del siglo XX se mantiene activo y ha ido creando un espacio propio en festivales, publicaciones y premios. El siglo XXI abre con la Tesis del Doctor Freddy Artiles proclamando a Pelusín del Monte Títere Nacional, trayendo, con este gesto el teatro de títeres como objeto de investigación, para su defensa y legitimación académica bajo el techo de la alta casa de estudios, Instituto Superior de Arte. Desde entonces algunas voces han deseado desencadenar la polémica oponiéndose, pero ninguna con un ejercicio serio de investigación, apenas desde la manifestación informal de la inconformidad.

\begin{abstract}
Caminaba por la calle Línea con Freddy y le decía que siendo de Guantánamo jamás había visto al tal Pelusín, así que muy nacional no era, y que me molestaba esa necesidad imperiosa que teníamos siempre de ponerle nombres pomposos a las cosas cuando Pelusín bien que podría quedarse tranquilo en sus "cuatro texticos". Freddy ni se inmutó con mis provocaciones; maestro como era, sonrió y contraatacó con una calma "madura" y me dijo un par de motivos por los cuales creía que el título honorario era justo. Sus razones están escritas en un excelente artículo del año 2006 titulado "Pelusín del Monte ¿Títere Nacional?"; sin embargo, lo más contundente no fueron sus certeros juicios, sino su pregunta de coda: No eres la única que se opone al título, pero ¿qué utilidad tiene en tu vida como investigadora dedicarle razones a esta batalla, cuando no tienes una propuesta mejor que la nada? (FAVIER, 2016:01)
\end{abstract}

Este testimonio, me coloca hoy en el deber de producir "algo mejor que la nada" para dialogar con mi maestro 15 años después de que me dijera: "haga teatro, después investigue". Porque no estaría investigando hoy si no fuera por él, por el respeto que me trasmitió, primero por la humanidad y luego por el oficio, me siento hoy en el deber, desde el futuro que él no alcanzo a vivir, de cuestionar a la luz del presente algunos asuntos que cruzan su tesis.

En lo que va de siglo, otras personas abrazaron su discurso trayendo consigo acciones concretas que bajo el auspicio de las instituciones gubernamentales van convirtiendo su gesto, la proclama, en "verdad", al menos sembrándolo en el imaginario colectivo. Ejemplo de ello es que hace unos meses nos consultaban desde el Ministerio de Educación el deseo de utilizar la imagen 
de Pelusín como personaje conductor del nuevo libro de lengua española que se diseña para aprender a leer en la enseñanza primaria.

Las cifras con respecto al repertorio activo de los grupos, con las que se inició la investigación para Uberlândia, inmediatamente remiten a la fragilidad de la tesis del Dr. Freddy Artiles. Pero no me detengo en los números. La isla de los fantasmas o la Revolución de los Juancitos, título dado a la conferencia en la 2da CENA ANIMADA me colocó ante varios problemas y en nuevos caminos.

¿Por qué estos hechos estadísticos no han sido tomados en cuenta por los numerosos teatrólogos que hoy se vinculan al teatro de títeres en Cuba a pesar de que en sus discursos e investigaciones la presencia de Javier Villafañe es ineludible, siendo un autor fundacional que ya aparece en los repertorios de las primeras compañías gestadas en la década de 50 del siglo XX cubano? Porque no es un autor cubano? La respuesta es multifactorial. Solo Norge Espinosa con motivos de la celebración del centenario de su natalicio tras un largo panegírico concluye: (...) Insisto: no todas las mencionadas cubren el amplio mapa de Villafañe en Cuba: aún pueden sumarse otros montajes, pues el eco del maese ha dado para esto y mucho más. (ESPINOSA, 2009:10) Incluso el propio Dr. Freddy Artiles en su prólogo a la antología publicada por Casa de las Américas con motivo del centenario de Villafañe al referirse a La calle de los fantasmas expresa:

Se trata, sin dudas, no solo de la pieza titiritera para niños más representada en su país de origen -la mayoría de los titiriteros argentino iniciaron su carrera con el repertorio de Villafañe y con La calle... como plato fuerte- sino también en todo el mundo del títere hispanoamericano, aparte de que han existido publicaciones y compañías con el nombre de sus protagonistas.

Dilucidar el por qué de ese hecho sería tan difícil como explicar por qué una determinada obra de cualquier género escapa al medio geográfico y a la época en que fue concebida para situarse en un primer plano y convertirse en un acontecimiento artístico mundial e intenporal, esto es, en un clasico. (ARTILES, 2009, 19)

Quizas sea hora de asumir el desafio, partiendo de asumir que las estadísticas mensionadas van más allá de la permanencia de un "clásico", para reconocer los mecanismos y el contexto socio-histórico que así lo propicia y cómo se expresa en este fenómeno la condición de cubanos en tiempo presente. 
Cuba alcanza su soberanía de España en 1901 bajo la intervención de los Estados Unidos. En los años subsiguientes y hasta la década del '30 entrarán más inmigrantes que en todos los siglos anteriores.

(...)Cuba recibió entre el fin de la guerra y 1930 más de un millón y cuarto de inmigrantes, número solo superado en América Latina de ese período por Argentina y Brasil. Vinieron más españoles a Cuba después de 1898 que durante la época colonial. Y también unos cuatrocientos mil caribeños en su mayoría haitiano y jamaiquinos.(...) El enorme torrente de inmigrantes- en su mayoría jóvenes- contribuyó a que Cuba tuviese casi cuatro millones de habitantes en 1931; de ellos el 21,5 \% no había nacido en la isla.( MARTÍNEZ HEREDIA, 2012:10)

En 1959 con el derrocamiento de la dictadura de Fulgencio Batista comienza un proceso revolucionario de alcance nacional. Hasta ese momento se había perpetuado un desarrollo desigual donde la actividad cultural se concentraba en la capital y en algunas ciudades del occidente, dejando en carestía al resto del país. Se acuñan así expresiones como "La Habana es la Habana y lo demás es monte”. En estas condiciones van a expresarse de un lado el discurso nacionalista afianzado, reedificado en las políticas culturales diseñadas por el estado socialista $\mathrm{y}$ del otro el subyacente complejo poscolonial del “subdesarrollado". En la implementación de planes para democratizar la cultura, se fundaron compañías por todas las provincias, se crearon escuelas, se trabajó en las comunidades. En la actualidad, las compañías titiriteras del país presentan, a mi modo de ver, atributos uniformados, mientras la mayoría de las personas no se salvan de la llegada de los productos globalizantes a través de los medios masivos de comunicación.

En este contexto traemos a discusión en nuestro estudio el asunto de la identidad y la autoafirmación, tamizadas por paradigmas coloniales como medida de legitimación, en los elementos mediante los cuales el Dr. Freddy Artiles construye su alegato para declarar a Pelusín del Monte Títere Nacional. De hecho el libro que posteriormente publicara se titula De Maccus a Pelusín, donde trazar una línea genealógica desde el teatro de títeres europeos hasta Cuba será uno de los pilares de su tesis. Dicha genealogía no se puede establecer de forma directa, pero de cualquier modo es colocada. Luego, de igual manera, los elementos de la identidad cubana esgrimidos, son apenas representativos de un sector de la población campesina cubana: elementos lexicales, género musical y culinaria 
típica, además de la indumentaria y el aspecto racial como blanco de cabellos rubios. Lo que deja fuera la posibilidad de que otros integrantes del entramado multicultural cubano, se reconozcan incluidos, representados, para un ejercicio de identificación forzoso frente a la invocación de la obra de arte como atributo de identidad nacional. Ante estos hechos me propongo trabajar con los postulados de Stuart Hall en cuanto a la noción de identidad cultural como un fenómeno en proceso y a la propia condición transcultural, llegando hasta el cuestionamiento de si necesitamos una "identidad", en cuanto categoría construida por los estamentos del poder imperante a la hora de aplicar políticas totalizadoras y apelar a los sentimientos nacionalistas con fines de control. Lo que podríamos hayar sintetizado así,

\begin{abstract}
En el momento en que un hecho histórico pasa bajo el signo del discurso, está sujeto a todas las "reglas" complejas formales a través de las cuales el lenguaje significa. Para decirlo en forma paradójica, el evento debe convertirse en una "historia/relato" antes de que pueda convertirse en un evento comunicativo .En ese momento las sub-reglas formales del discurso están "en función dominante", sin, por supuesto subordinar la existencia del evento histórico así significado, las relaciones sociales en las cuales las reglas trabajan o las consecuencias sociales o políticas del evento que ha sido significado de este modo(...)La identidad es un concepto de este tipo, que funciona "bajo borradura" en el intervalo entre inversión y surgimiento; una idea que no puede pensarse a la vieja usanza, pero sin la cual ciertas cuestiones clave no pueden pensarse en absoluto. (HALL, 2003:14)
\end{abstract}

Para Hall (2003) la identificación en el lenguaje del sentido común, se construye sobre la base del reconocimiento de algún origen común o unas características compartidas con otra persona o grupo o con un ideal, y con el vallado natural de la solidaridad y la lealtad establecidas sobre este fundamento. En contraste con el "naturalismo" de esta definición, el enfoque discursivo ve la identificación como una construcción, un proceso nunca terminado: siempre "en proceso". No está determinado, en el sentido de que siempre es posible "ganarlo" o "perderlo", sostenerlo o abandonarlo. Aunque no carece de condiciones determinadas de existencia, que incluyen los recursos materiales y simbólicos necesarios para sostenerla, la identificación es en definitiva condicional y se afinca en la contingencia. Obedece a la lógica del más de uno. Y puesto que como proceso actúa a través de la diferencia, entraña un trabajo discursivo, la marcación y ratificación de límites simbólicos, la producción de “efectos de 
frontera”. Necesita lo que queda afuera, su exterior constitutivo, para consolidar el proceso.

Ante la incongruencia entre la proclama académica por un "títere nacional" y los hechos palpables en las estadísticas presentadas, las preguntas de Hall ofrecen un instrumento de análisis al apuntar hacia cuáles son los mecanismos mediante los cuales los individuos, como sujetos, se identifican (o no se identifican) con las "posiciones" a las cuales se los convoca; cómo se modelan, estilizan, producen y "actúan" esas posiciones, y por qué nunca lo hacen completamente, de una vez y para siempre, mientras que otros no lo hacen nunca o se embarcan en un proceso agonístico constante de lucha, resistencia, negociación y adaptación a las reglas normativas o reguladoras con las que se enfrentan y a través de las cuales se autorregulan. Por lo que Hall concluye que

(...) el cuestionamiento y la teorización de la identidad son un asunto de considerable significación política que probablemente sólo será promovido cuando tanto la necesidad como la "imposibilidad" de las identidades, y la sutura de lo psíquico y lo discursivo en su constitución, se reconozcan de manera plena e inequívoca. (HALL, 2003:37)

Reconocer el impacto de la obra de Javier Villafañe, no solo en Cuba, sino para toda la región, nos lleva a buscar cuales elementos de manera transcultural, dan lugar en la obra de Javier a un producto nuevo, que se legitima en sí mismo y cuya evolución se afianza en la manera en que sus propias características son matrices para la expresión genuina por parte de los nacidos de este lado de la mar océano. ¿Acaso en ese germen de lo "nuestro" se encuentran las respuestas para comprender por qué al margen y al centro de las políticas culturales del estado socialista en los últimos 50 años, incluso antes, podríamos considerar la obra de Javier Villafañe matriz nutricia del teatro de títeres en Cuba? ¿Podríamos detectar en términos transculturales qué elementos provienen de la tradición europea y cuales son expresión de la vida que se construye en las condiciones histórico-sociales de este lado del mar? ¿Qué condiciones de la Cuba socialista son propicias para el crecimiento y proliferación de la obra de Javier Villafañe como constante en la producciones titiriteras? ¿Hasta qué punto esta elección reiterada por parte de los creadores es un acto más o menos consiente de trasgresión y contesta, de resistencia cultural signada por la propia naturaleza 
del teatro de títeres? ¿Cuáles son las trazas de hibridación experimentadas por la obra de Javier Villafañe para su existencia y evolución en el territorio cubano?

Algunas publicaciones anteriores tocan a Javier Villafañe pero no lo observan en su dimensión cubana, es el caso de Yudd Favier en su tesis de grado La Dramaturgia Titiritera Cubana: sus característica, de 2004, o el propio Freddy Artiles en Teatro y Dramaturgia para niños en la Revolución, de 2009; quien en el prólogo a La Calle de los Fantasmas y otras obras de Títeres, publicado por Casa de las Américas, 2009, con motivo del centenario de Javier Villafañe, presenta al autor sin profundizar en el papel activo de su repertorio en el teatro de títeres cubano a la altura del nuevo siglo. Armando Morales, a quien le debemos buena parte de la difusión de la obra de Javier Villafañe en Cuba, en su libro, ¿En la luz o en la sombra? El Titere, aunque apunta hacia una conciencia más explícita de lo americano:

Alejandro de Humboldt había apuntado que "La américa es una nueva dimensión de la humanidad" y, ciertamente, en el teatro de títeres, o con más exactitud, en los personajes-títeres de tan específica teatralidad, están presentes las pautas y las medidas de los complejos procesos que distinguen a nuestros pueblos. La imagen del títere en el Nuevo Mundo, en suma, es diferente a la heredada. No inferior, tampoco superior: simplemente distinta. (MORALES, 2002: 53)

Con todo, no consigue sustraerse a la tentación de proclamar como un producto "nacional” a Pelusín del Monte, suscribiendo la tesis de Artiles.

Entre las naciones americanas, probablemente, Cuba y Brasil son de las que más elementos histórico-sociales comparten, en cuanto a composición multicultural, situación doblemente poscolonial (Europa, Estados Unidos), fechas tardías de emancipación y abolición de la esclavitud, y coincidencia en los grupos étnicos trasladados por la trata esclavista en los mismos períodos. Por lo que he podido escuchar durante las mesas temáticas organizadas en CENA ANIMADA 2016, hay grandes semejanzas en los procesos de asimilación de la producción titiritera argentina, para la conformación y crecimiento del movimiento titiritero en el siglo XX y lo que va del XXI al menos en la región sur del país. 
Por todo esto he querido compartir el curso que ha tomado la investigación al paso de un año y con ello agradecer nuevamente a CENA ANIMADA por trazar el camino, colocándonos frente al espejo para una mirada crítica del modo en que nos hemos contado y entendido. Pero sobre todas las cosas creo necesario ofrecer un punto vista que esté en condiciones de discutir posiciones euro céntricas que vienen lastrando los estudios sobre el teatro de títeres en Cuba, manifestando una polémica silenciada, disminuida, que alcanza ya casi 20 años. Y con ello, contribuir a la construcción de un discurso de enfoque transcultural para la comprensión de una zona de identificación actualizada, expandida, que indique hacia la descolonización por medio de la toma de decisiones que afectan las políticas culturales de la nación.

Apenas se conservan las tradiciones sanjuaneras en el Camagüey, pero aún gracias al teatro de títeres de Javier Villafañe seguimos contando en Cuba historias de diablos. De este lado mágico del mundo, el Maeses Trotamundos nos mostró, por medio de las aventuras del valiente Juancito, lo real-maravilloso que está debajo de los fantasmas: hombres, mortales ensabanados a los que no hay que tener miedo de enfrentar...

¡Coraje para los Juancitos y las Marías de Nuestra América!

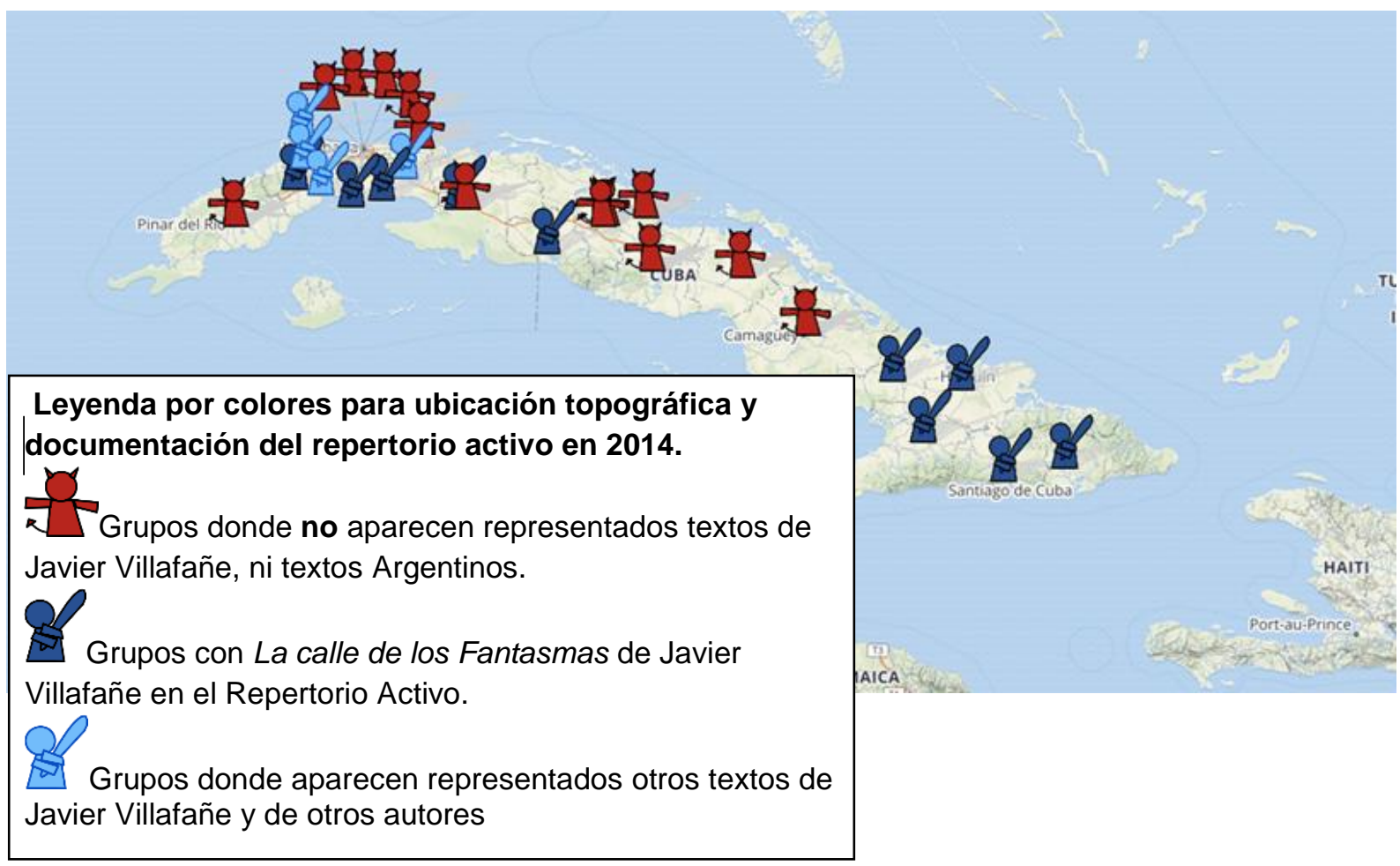




\section{REFERENCIAS}

ARTILES, Freddy. "Las Aventuras de Maese Villafañe". In: La Calle de los fantasmas y otras obras de títeres. La Habana, Fondo editorial Casa de las Américas, 2009.

ESPINOSA, Norge. Cien retablos Villafañe. La Habana: La Jiribilla, 2009. http://epoca2.lajiribilla.cu/2009/n444 11/444 21.html

FAVIER, Yudd. Catálogo UNIMA Cuba. La Habana: Consejo Nacional de las Artes Escénicas, Cuba, 2014.

“Boxeando con mi maestro". La Habana: La Jiribilla, 2016.

http://www.lajiribilla.cu/articulo/boxeando-con-mi-maestro

HALL, Stuart. ¿¿Quién necesita “identidad”?” en Hall, Stuarty Du Gay, Paul (comps.), Cuestiones de identidad cultural, Buenos Aires: Amorrortu, 2003.

HALL, Stuart. Discurso y Poder. Huancayo, Perú. 2013. https://estudioscultura.

MARTÍ, José. "Nuestra América". In: Nuestra América. Caracas, Biblioteca Ayacucho, 2005. Consultado en:

http://www.brouillondeculture.fr/imagesmagasins/divers/5184558102.pdf

MARTÍNEZ HEREDIA, Fernando. Identidad y cultura nacionales: Historia y temas actuales. Disponible en

https://revista.ecaminos.org/article/identidad-y-cultura-nacionales-historia- $y$ temas--2/ Consultado 13/03/2017

MEDINA, Pablo. Javier Villafañe. Antología. Obra y recopilaciones. Buenos Aires: Editorial Sudamericana, 1990.

MORALES, Armando. ¿En la luz o en la sombra? El Títere. La Habana: Ediciones UNIÓN, 2002. 


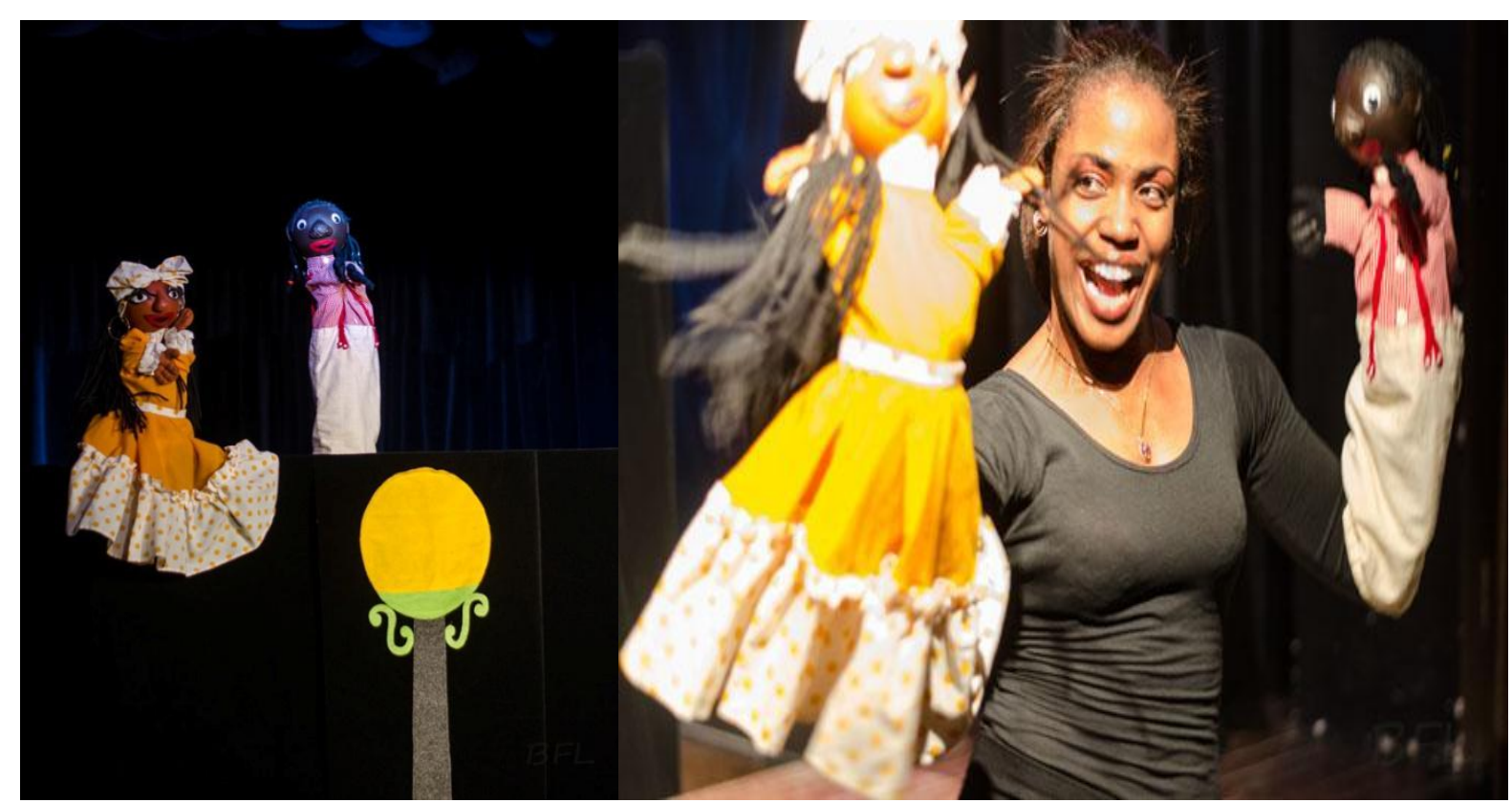

El Negrito y los Fantasmas. Yanelis Vignier. El Arca, 2015. Acervo de la compañía.
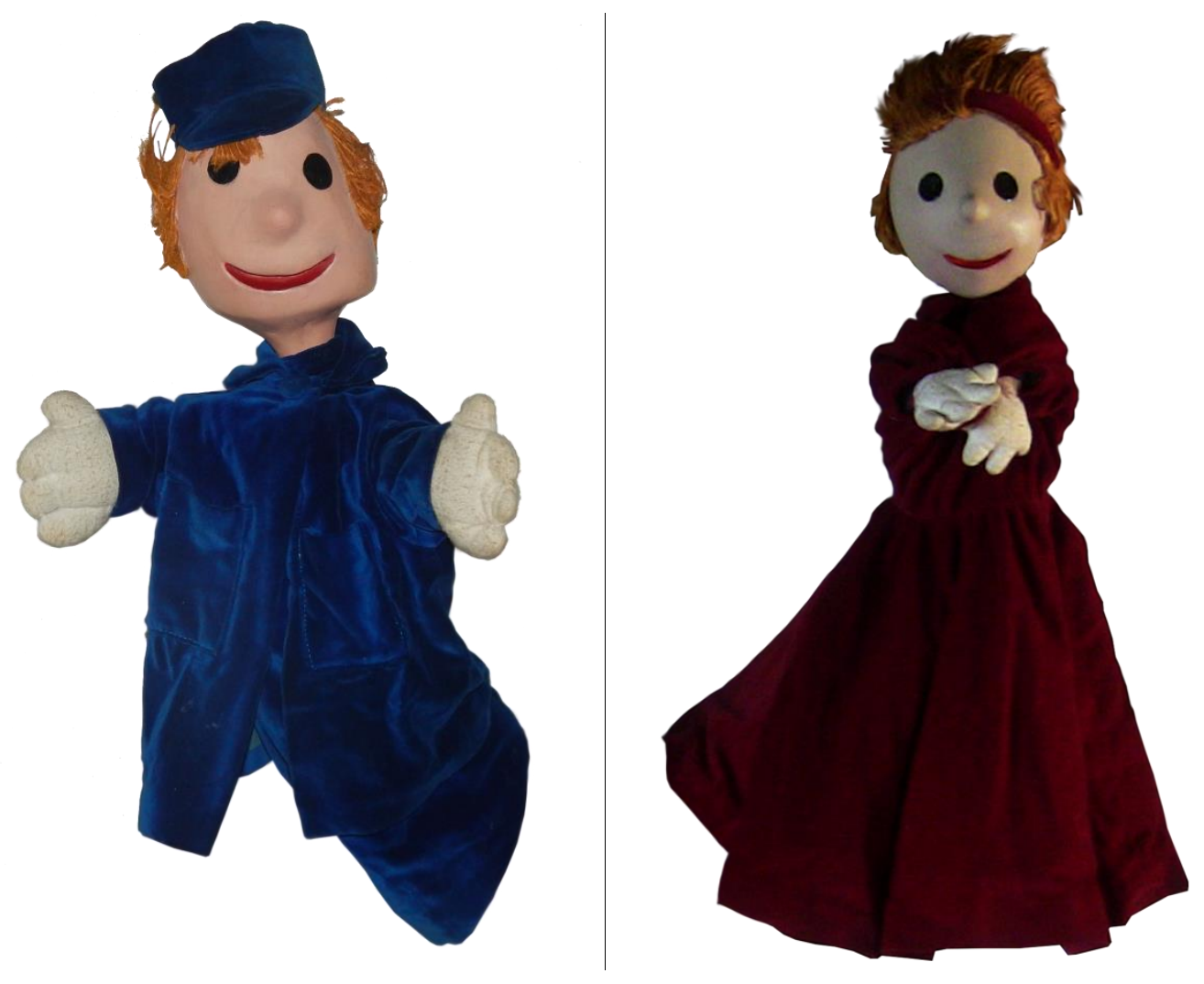

Juancito y Maria. Teatro de Muñecos de la Habana, Nicolás Lourerio, 1965.Colección sala Cubana: El Arca, Teatro Museo de Títeres.

Recebido em agosto de 2018.

Aprovado em outubro de 2018.

Publicado em dezembro de 2018. 